\title{
Epidemiology and Outcome of Candidemia in ICU, Mashhad, a 6-Year Multi-Center Study
}

\author{
Yeganeh Ahrari ${ }^{1}$, Amin Bojdy ${ }^{2 *}$, Mona Najafi ${ }^{3}$, Mahnaz Arian ${ }^{4}$, Nasrin khosravi Zeenyani ${ }^{5}$ \\ ${ }^{1}$ Assistant, Department of infectious Diseases and Tropical Medicine, Imam Reza Hospital, Mashhad University of Medical Sciences, Mashhad, Iran. \\ ${ }^{2}$ Assistant Professor, Infectious Department, Faculty of Medicine, Mashhad University of Medical Sciences, Mashhad, Iran \\ ${ }^{3}$ Assistant Professor, Clinical Research Development Unit, Imam Reza Hospital, Mashhad University of Medical Sciences, Mashhad, Iran. \\ ${ }^{4}$ Assistant Professor, Department of infectious Diseases and Tropical Medicine, Imam Reza Hospital, Mashhad University of Medical Sciences, \\ Mashhad, Iran.
}

${ }^{5}$ Infection Control Supervisor, Imam Reza Hospital, Mashhad University of Medical Sciences, Mashhad, Iran

*Corresponding Author: Amin Bojdy, Assistant Professor, Infectious Department, Faculty of Medicine, Mashhad University of Medical Sciences, Mashhad, Iran.

Received date: November 22, 2021; Accepted date: December 10, 2021; Published date: January 05, 2022

Citation: Yeganeh Ahrari, Amin Bojdy, Mona Najafi, Mahnaz Arian, Nasrin khosravi Zeenyani (2022) Epidemiology and Outcome of Candidemia in ICU, Mashhad, a 6-Year Multi-Center Study. J. Pharmaceutics and Pharmacology Research, 5(2); DOI:10.31579/2693-7247/041

Copyright: (C) 2022 Amin Bojdy, This is an open access article distributed under the Creative Commons Attribution License, which permits unrestricted use, distribution, and reproduction in any medium, provided the original work is properly cited.

\begin{abstract}
Summary
Background and aim: candidemia is a state that usually happens in immunocompromised patients. Thus it is more prevalent in ICU patients. This status brings mortality and morbidity; however, the outcome is various in different ICU care settings. The aim of this study is to assess epidemiology of outcome of candidemia in ICU in Mashhad during a 6-year period.

Method: in a cross-sectional study between 2012 and 2018 in different ICU centers affiliating with Mashhad University of Medical Sciences, data of candidemia patients were extracted from hospital information system. These data were demographic, past medical history, result of the culture, and antifungal treatment.

Result: totally, 55 patients ( 22 men and 33 women) were included in the study. The mean age of the patients was $45.9 \pm 1.9$ years. Furthermore, the mean duration of hospitalization and the mean duration of ICU care were 43 and 37 days, respectively. Five patients had a history of immunosuppressive treatment and four patients were prescribed antifungal treatment in their past medical history (all with fluconazole and none with Itraconazole). Eighteen patients received caspofungin, eleven Amphotericin B treatment, and two fluconazole with no significant difference in outcome of the patients regarding antifungal type. In case of coincident antibiotic treatment, Carbapenems were prescribed in 43 patients, Glycopeptides in 48 patients, 25 patients had Cephalosporin treatment, and 13 patients had Fluoroquinolone treatment with no significant difference regarding the antibiotic type.
\end{abstract}

Conclusion: The mortality percent of candidemia in ICU was 69.1 within mean time of 37 days. Furthermore, there was no significant difference in outcome of the patients regarding using Caspofungin or Amphotericin. Timely initiation of antifungal regarding to the culture result may bring better outcomes.

Key words: drug discovery; therapeutic drug; COVID-19

Introduction

Candida family is a vast group of molds presenting in many surfaces especially as a saprophyte yeast [1]. This fungus is present in many parts of the human body, especially mucosal surfaces and as a commensal microbiota can adapt environmental changes [2]. These predisposing factors may be immunocompromising conditions such as human immunodeficiency virus (HIV) infection, using immunosuppressive treatments, and chemotherapy, or presence of some chronic diseases such as diabetes, hematologic malignancies, end stage renal disease, liver disease, and etc [3, 4].

However, candidiasis mainly is caused by C. albicans, C. parapsilosis, C. glabrata, C. tropicalis, and C. krusei [5]. Among several candida species C. albicans is the major pathologic specie that is responsible for $46.3 \%$ of 
cases. In the second step C. glabrata stands with $24.4 \%$ of the found species in cultures [6]. The morbidity and mortality of the candidiasis mostly depends on the immunity response of the host, virulence of the candida specie and strain, and anatomical site of infection [7,8].

The invasive infestation of candida as blood borne disease is called candidemia. This condition brings $20 \%$ to $40 \%$ mortality rate [9]. The estimated financial cost at an episode of hospitalization due to candidemia is around $\$ 25,000-\$ 55,000$ in US [10]. In Iran, it is reported that $70.4 \%$ of invasive fungal infections are due to the infestation of candida [11]; however, lack of sufficient epidemiologic data is sensed through literature review [12]. The aim of our study is to assess epidemiology and outcome of candidemia in an intensive care unit in Ghaem and Imam Reza Hospital, Mashhad, Iran, between 2012 and 2018.

\section{Method}

We conducted a cross-sectional study in Emam Reza and Ghaem Hospitals, which are educational hospitals of Mashhad University of Medical sciences, between 2012 and 2018. Presuming that a vast number of candidemia cases are found in intensive care units (ICUs), this study was conducted on ICU patients. First of all, Candidemic patients, those who had positive blood culture for candida, were extracted from hospital information system (HIS) using the medical records of the ICU patients in this data base. Total steps of the study was in line with the Helsinki ethics declaration and ethics committee of Mashhad University of Medical Sciences approved all the ethical points in our study.

\section{Result}

Totally, 55 patients were included in the study consisting of 22 men (40\%) and 33 women $(60 \%)$. The mean age of the patients was $45.9 \pm 1.9$ years.
The mean duration of hospitalization in total was 43 days and the mean duration of ICU admission was 37 days. Fourteen patients had diabetes, 6 suffered from end stage-renal disease, 27 had cardiovascular disease, 4 had a history of surgery, and one patient had underwent organ transplantation. None of the patients had a history of liver disease, hematologic malignancy, and chemotherapy. Five patients had a history of immunosuppressive treatment. Four patients had a history of antifungal treatment and all of them had a history of previous fluconazole therapy, and none of them have taken Itraconazole.

24 patients $(43.6 \%)$ received no antifungal treatment. 11 patients had no antifungal treatment and 13 were expired before receiving antifungal treatment. In case of antifungal treatment in ICU admission, 18 patients $(32.7 \%)$ were prescribed caspofungin, 11 (20.0\%) had Amphotericin B treatment, and $2(3.6 \%)$ had fluconazole treatment. Data regarding coincident antibiotic treatment showed that Carbapenems were prescribed in 43 patients (78.2\%), Glycopeptides in 48 patients (87.3\%), 25 patients (45.5\%) had Cephalosporin treatment, and 13 patients $(23.6 \%)$ had Fluoroquinolone treatment. Antifungal treatment was initiated in 15 cases (27.3\%) before a period of two weeks, in 8 cases $(14.5 \%)$ within two weeks, and in seven cases (12.7\%) in a timing of more than two weeks. Seventeen cases expired in a period of less than one week and $19(34.5 \%)$ patients expired in a timing of more than one week from the positive blood culture for candida. Other body fluid culture was negative in $63.6 \%$ of the patients. Nineteen patients $(34.5 \%)$ had a urinary culture of candida and only one case $(1.8 \%)$ had a peritoneal fluid positive for candida. Five patients $(9.1 \%$ ) also had received prednisolone (Table 1). All of the patients had urinary catheter with a mean duration of 33.7 days. Also, 46 patients had CV line with a median duration of 22 days.

\begin{tabular}{|c|c|c|c|}
\hline \multicolumn{3}{|l|}{ Feature } & Statistics \\
\hline \multirow[t]{5}{*}{ Antifungal treatment $\mathrm{N}(\%)$} & \multicolumn{2}{|l|}{ Caspofungin } & $18(32.7)$ \\
\hline & \multicolumn{2}{|l|}{ Amphotericin B } & $11(20.0)$ \\
\hline & \multicolumn{2}{|c|}{ Fluconazole } & $2(3.6)$ \\
\hline & \multicolumn{2}{|c|}{ Absence of antifungal treatment } & $11(20.0)$ \\
\hline & \multicolumn{2}{|c|}{ Expired before receiving antifungal treatment } & $13(23.6)$ \\
\hline \multirow[t]{8}{*}{ Antibiotic treatment } & \multirow[t]{2}{*}{ Carbapenem } & Yes & $43(78.2)$ \\
\hline & & $\mathrm{No}$ & $12(21.8)$ \\
\hline & \multirow[t]{2}{*}{ Glycopeptide } & Yes & $48(87.3)$ \\
\hline & & No & $6(10.9)$ \\
\hline & \multirow[t]{2}{*}{ Cephalosporin } & Yes & $25(45.5)$ \\
\hline & & No & $30(55.5)$ \\
\hline & \multirow[t]{2}{*}{ Fluoroquinolone } & Yes & $13(23.6)$ \\
\hline & & No & $42(76.4)$ \\
\hline \multirow{4}{*}{$\begin{array}{l}\text { The time of antifungal treatment initiation in relation } \\
\text { to the time of present positive culture for candida } \mathrm{N} \\
(\%)\end{array}$} & \multicolumn{2}{|c|}{ Before the presence of positive blood culture } & $5(9.1)$ \\
\hline & \multicolumn{2}{|c|}{48 hours after the presence of positive blood culture } & $23(41.8)$ \\
\hline & \multicolumn{2}{|c|}{ Immediately after presence of positive blood culture } & $3(5.5)$ \\
\hline & \multicolumn{2}{|c|}{ Received no antifungal treatment } & $24(43.6)$ \\
\hline \multirow{4}{*}{$\begin{array}{l}\text { The time of antifungal treatment continuation after } \\
\text { presence of negative candida culture } \mathrm{N}(\%)\end{array}$} & \multicolumn{2}{|c|}{$<2$ weeks } & $15(27.3)$ \\
\hline & \multicolumn{2}{|l|}{ Within 2 weeks } & $8(14.5)$ \\
\hline & \multicolumn{2}{|l|}{$>2$ weeks } & $7(12.7)$ \\
\hline & \multicolumn{2}{|c|}{ Expired with no antifungal treatment } & $25(45.5)$ \\
\hline \multirow[t]{2}{*}{ Outcome of the patients at discharge $\mathrm{N}(\%)$} & \multicolumn{2}{|c|}{ Alive } & $17(30.9)$ \\
\hline & \multicolumn{2}{|l|}{ Dead } & $38(69.1)$ \\
\hline \multirow[t]{2}{*}{ Prednisolone treatment $\mathrm{N}(\%)$} & \multicolumn{2}{|l|}{ Yes } & $5(9.1)$ \\
\hline & \multicolumn{2}{|l|}{ No } & $50(90.9)$ \\
\hline \multirow[t]{3}{*}{ Candida culture from other body fluids $\mathrm{N}(\%)$} & \multicolumn{2}{|c|}{ Negative } & $35(63.6)$ \\
\hline & \multicolumn{2}{|c|}{ Before positive blood culture } & $17(30.9)$ \\
\hline & \multicolumn{2}{|c|}{ After positive blood culture } & $3(5.5)$ \\
\hline Type of candida cultivation $\mathrm{N}(\%)$ & Negative & & $35(63.6)$ \\
\hline
\end{tabular}




\begin{tabular}{|l|l|l|}
\hline \multirow{2}{*}{$\begin{array}{l}\text { The duration between positive candida culture and } \\
\text { patient's expiration }\end{array}$} & Urine culture & $19(34.5)$ \\
\cline { 2 - 3 } & Peritoneal fluid & $1(1.8)$ \\
\cline { 2 - 3 } & SOne week & $17(30.9)$ \\
\cline { 2 - 3 } & One week & $2(3.6)$ \\
\cline { 2 - 3 } & None week & $19(34.5)$ \\
\hline
\end{tabular}

Table 1. Different antibiotic and antifungal treatment, treatment outcome, and results of positive candida from body fluids

Most of the patients (23 cases or $41.8 \%$ ) received treatment during the first 48 hours after the presence of positive blood culture. The outcome of the patients showed that 17 patients $(30.9 \%)$ were alive at the end of study and 38 patients $(69.1 \%)$ were dead (table 2$)$. There were no significant difference in outcome of the patients regarding using Carbapenem ( $\mathrm{p}=0.227)$, Glycopeptide (0.999), Cephalosporin $(\mathrm{p}=0.562)$, or Fluoroquinolone $(\mathrm{p}=0.500)$. $29.4 \%$ of the patients who received
Caspofungin, were alive, $63.6 \%$ of those who received Amphotericin, and $33.3 \%$ of the patients who received Fluconazole were alive. There was no significant difference regarding the outcome of Caspofungin and Amphotericin $(\mathrm{p}=0.074)$. Table 2 shows the details of the above mentioned. 51 patients $(92.7 \%)$ received wide spectrum antibiotic therapy.

\begin{tabular}{|c|c|c|c|c|c|c|}
\hline \multicolumn{4}{|l|}{ Feature } & Alive & Dead & $\mathrm{p}$ value \\
\hline \multirow{8}{*}{$\begin{array}{l}\text { Antibiotic treatment } \mathrm{N} \\
(\%)\end{array}$} & \multirow{2}{*}{\multicolumn{2}{|c|}{ Carbapenem }} & Yes & $15(34.9)$ & $28(65.1)$ & \multirow[t]{2}{*}{$0.227 * *$} \\
\hline & & & No & $2(16.7)$ & $10(83.3)$ & \\
\hline & \multirow{2}{*}{\multicolumn{2}{|c|}{ Glycopeptide }} & Yes & $15(30.6)$ & $34(69.4)$ & \multirow[t]{2}{*}{$0.999 * *$} \\
\hline & & & No & $2(33.3)$ & $4(66.7)$ & \\
\hline & \multirow{2}{*}{\multicolumn{2}{|c|}{ Cephalosporin }} & Yes & $9(36.0)$ & $16(64.0)$ & \multirow[t]{2}{*}{$0.562 *$} \\
\hline & & & No & $8(26.7)$ & $22(73.3)$ & \\
\hline & \multirow{2}{*}{\multicolumn{2}{|c|}{ Fluoroquinolone }} & Yes & $5(38.5)$ & $8(61.5)$ & \multirow[t]{2}{*}{$0.500 * *$} \\
\hline & & & No & $12(28.6)$ & $30(71.4)$ & \\
\hline \multirow{3}{*}{\multicolumn{2}{|c|}{ Antifungal treatment $\mathrm{N}(\%)$}} & \multicolumn{2}{|c|}{ Caspofungin } & $5(29.4)$ & $12(70.6)$ & \multirow[t]{3}{*}{-} \\
\hline & & \multicolumn{2}{|c|}{ Amphotericin } & $7(63.6)$ & $4(36.4)$ & \\
\hline & & \multicolumn{2}{|c|}{ Fluconazole } & $1(33.3)$ & $2(66.7)$ & \\
\hline \multirow{2}{*}{\multicolumn{2}{|c|}{$\begin{array}{l}\text { New generation antifungal } \\
\text { treatment }\end{array}$}} & \multicolumn{2}{|c|}{ Caspofungin } & $5(29.4)$ & $12(70.6)$ & \multirow[t]{2}{*}{$0.074 * *$} \\
\hline & & \multirow{2}{*}{\multicolumn{2}{|c|}{$\begin{array}{l}\text { Amphotericin } \\
\text { Yes }\end{array}$}} & $7(63.6)$ & $4(36.4)$ & \\
\hline \multirow{2}{*}{\multicolumn{2}{|c|}{ Receiving treatment }} & & & $4(30.8)$ & $9(69.2)$ & \multirow[t]{2}{*}{$0.990 * *$} \\
\hline & & \multicolumn{2}{|l|}{ No } & $13(31.0)$ & $29(69.0)$ & \\
\hline
\end{tabular}

*Fisher's exact test; ${ }^{* *}$ chi-square test

Table 2. Comparison of the patients' outcome regarding antibiotic or antifungal treatment.

Table 3 also shows the distribution of the patients' outcome regarding the timing of the initiation of anti-fungal therapy. 40 percent of the patients who had a negative blood culture for candida in less than two weeks were alive, however, this was 71.4 percent in patients with a period more than two weeks. It has also been shown that $66.7 \%$ of the patients who received antifungal treatment immediately after presence of positive blood culture were alive. Only 2 cases $(16.7 \%)$ of the patients who received no treatment were alive.

\begin{tabular}{|c|c|c|c|}
\hline \multicolumn{2}{|l|}{ Feature } & Alive & Dead \\
\hline \multirow{4}{*}{$\begin{array}{l}\text { The time between antifungal } \\
\text { treatment initiation and } \\
\text { presence of negative candida } \\
\text { culture } \mathrm{N}(\%)\end{array}$} & $<2$ weeks & $6(40.0)$ & $9(60.0)$ \\
\hline & Within 2 weeks & $2(25.0)$ & $6(75.0)$ \\
\hline & $>2$ weeks & $5(71.4)$ & $2(28.6)$ \\
\hline & Expired with no antifungal treatment & $4(16.0)$ & $21(84.0)$ \\
\hline \multirow{4}{*}{$\begin{array}{l}\text { The time of antifungal } \\
\text { treatment initiation in relation } \\
\text { to the time of present positive } \\
\text { culture for candida } \mathrm{N}(\%)\end{array}$} & Before the presence of positive blood culture & $2(40.0)$ & $3(60.0)$ \\
\hline & 48 hours after the presence of positive blood culture & $9(39.1)$ & $14(60.9)$ \\
\hline & Immediately after presence of positive blood culture & $2(66.7)$ & $1(33.3)$ \\
\hline & Received no antifungal treatment & $4(16.7)$ & $20(83.3)$ \\
\hline
\end{tabular}

Table 3. Frequency of alive or dead cases regarding time of antifungal initiation and the time of status of culture for candida

\section{Discussion}

Yapar et al. [13] conducted a similar study on the incidence risk factors and outcome of the candidemia in patients in ICU and compared it with those ICU patients without candidemia. They reported an incidence of
12.3 per 1000 admissions in ICU. In our study also, 83.6 percent of the patients had central venous catheter. It seems that catheterization may be a risk factor for candidemia. Our study showed no difference in the outcome of the patients recieving Carbapenems, Glycopeptide, Cephalosporins, or Fluoroquinolones antibiotic classes. They reported a 
crude mortality rate of 43.9 percent at 30 days ICU residency. In our study with a mean ICU stay of 37 days, 69.1 percent of patients were expired. Literature review of the studies supported that about one third of candidemic cases happen in medical or surgical intensive care units and a mortality rate around 50 to 60 percent is expected for these patients [1416]. These statistics are similar to our findings; however, mortality was slightly higher in our study.

The other point of our study was that we found no significant difference regarding using caspofungin or amphotericin as the treatment with better outcome in patients' survival. A recent systematic review and metaanalysis out of eight relevant articles revealed no difference between echinocandins, voriconazole, or amphotericin B formulations as the first choice treatment and the regarding outcome of the critically ill patients [17]. Other studies on ICU patients reported no difference regarding the choice of antifungal treatment and the outcome of the patients. GarnachoMontero et al. [18] in a Spanish retrospective study reported that the mortality rate was $37.4 \%$ in ICU patients who were treated with fluconazole and $31.9 \%$ in ICU patients under echinocandin treatment and this difference was not significant. Nagy et al. [19] in another study in ICU patients reported that treatment with fluconazole is not inferior than caspofungin, micafungin or amphotericin B in the outcome of candidemia patients. Mora-Durate et al. [20] also reported that caspofungin is at least as effective as amphotericin B for the treatment of invasive candidiasis and, more specifically, candidemia. It seems that the main predisposing factor for candidemia is the virulence of candida specie [21].

However, the main limit of the studies in the case of candidemia, especially those in intensive care units, is that the number of candidemia cases are few. Our study also had a total number of 55 candidemia cases and we tried to reach this sample size by adding two tertiary health centers to our study sample. It seems that the studies in case of candidemia should be done multi-centric. The larger sample size can overcome the limits in analyses. Putting this shortcoming away, our study was among the few studies in candidemia in ICU and especially in Iran. This can further help researchers to complete the gap in the data regarding candidemia in ICU.

\section{Conclusion}

Our study showed that 69.1 percent of the cases expired within a mean ICU stay of 37 days. Furthermore, there was no significant difference in outcome of the patients regarding using Caspofungin or Amphotericin. Our results also showed that timely initiation of antifungal regarding to the culture result may bring better outcomes as $66.7 \%$ of the patients who received antifungal immediately after a positive blood culture of candida survived.

\section{Acknowledgment}

The authors wish to express their appreciation for the financial support of Mashhad University of Medical Sciences and We would like to thank the clinical research development unit, Imam Reza Hospital, Mashhad University of Medical Sciences, for their assistance in this manuscript.

\section{Conflict of Interest}

Authors have declared that no competing interests exist.

\section{References}

1. Turner SA, Butler G. (2014) The Candida pathogenic species complex. Cold Spring Harbor perspectives in medicine. 4(9):a019778.
2. Whaley SG, Berkow EL, Rybak JM, Nishimoto AT, Barker KS, Rogers PD. (2017) Azole antifungal resistance in Candida albicans and emerging non-albicans Candida species. Frontiers in microbiology. 7:2173.

3. Canela HMS, Cardoso B, Vitali LH, Coelho HC, Martinez R, Ferreira MEdS. (2018) Prevalence, virulence factors and antifungal susceptibility of Candida spp. isolated from bloodstream infections in a tertiary care hospital in Brazil. Mycoses. 61(1):11-21.

4. Dadar M, Tiwari R, Karthik K, Chakraborty S, Shahali Y, Dhama K. (2018) Candida albicans-Biology, molecular characterization, pathogenicity, and advances in diagnosis and control-An update. Microbial pathogenesis. 117:128-38.

5. Andes DR, Safdar N, Baddley JW, Alexander B, Brumble L, Freifeld A, et al. (2016) The epidemiology and outcomes of invasive Candida infections among organ transplant recipients in the United States: results of the Transplant-Associated Infection Surveillance Network (TRANSNET). Transplant Infectious Disease. 18(6):921-31.

6. Montravers P, Leroy O, Eckmann C. (2015) Intra-abdominal candidiasis: it's still a long way to get unquestionable data. Springer.

7. Jabra-Rizk MA, Kong EF, Tsui C, Nguyen MH, Clancy CJ, Fidel PL, et al. (2016) Candida albicans pathogenesis: fitting within the host-microbe damage response framework. Infection and immunity. 84(10):2724-39.

8. Thompson DS, Carlisle PL, Kadosh D. (2011) Coevolution of morphology and virulence in Candida species. Eukaryotic cell. 10(9):1173-82.

9. Gunsalus KT, Tornberg-Belanger SN, Matthan NR, Lichtenstein AH, Kumamoto CA. (2016) Manipulation of host diet to reduce gastrointestinal colonization by the opportunistic pathogen Candida albicans. MSphere. 1(1).

10. Groth CM, Dodds-Ashley ES. (2016) Fungal Infections in the ICU.

11. Ahmadi A, Ardehali SH, Beigmohammadi MT, Hajiabdolbaghi M, Hashemian SMR, Kouchek M, et al. (2014) Invasive candidiasis in intensive care unit; consensus statement from an Iranian panel of experts, July 2013. JRSM open. 5(3):2042533313517689.

12. Zand F, Moghaddami M, Davarpanah MA, Masjedi M, Nikandish R, Amanati A, et al. (2016) Invasive fungal infections in critically-ill patients: A literature review and position statement from the IFI-clinical forum, Shiraz, Iran. Biosci Biotechnol Res Communicat. 9(3):371-81.

13. Yapar N, Akan M, Avkan-Oguz V, Ergon CM, Hancer M, Doluca M. (2019) Risk factors, incidence and outcome of candidemia in a Turkish intensive care unit: a five-year retrospective cohort study. Anaesthesia, Pain \& Intensive Care. 265-71.

14. Colombo AL, Guimarães T, Sukienik T, Pasqualotto AC, Andreotti R, Queiroz-Telles F, et al. (2014) Prognostic factors and historical trends in the epidemiology of candidemia in critically ill patients: an analysis of five multicenter studies sequentially conducted over a 9-year period. Intensive care medicine. 40(10):1489-98.

15. Marriott DJ, Playford EG, Chen S, Slavin M, Nguyen Q, Ellis D, et al. (2009) Determinants of mortality in non-neutropenic ICU patients with candidaemia. Critical Care. 13(4):R115.

16. de Molina FJG, León C, Ruiz-Santana S, Saavedra P. (2012) Assessment of candidemia-attributable mortality in critically ill patients using propensity score matching analysis. Critical Care. 16(3):R105. 
17. Keane S, Geoghegan P, Povoa P, Nseir S, Rodriguez A, MartinLoeches I. (2018) Systematic review on the first line treatment of amphotericin B in critically ill adults with candidemia or invasive candidiasis. Expert review of anti-infective therapy. 16(11):839-47.

18. Bennett JE, Powers JH. (2018) Candidemia In the Intensive Care Unit: Does initial antifungal matter? Critical care medicine. 46(3):482.

19. Nagy F, Tóth Z, Bozó A, Czeglédi A, Rebenku I, Majoros L, et al. (2019) Fluconazole is not inferior than caspofungin, micafungin or amphotericin $\mathrm{B}$ in the presence of $50 \%$ human serum against Candida albicans and Candida parapsilosis biofilms. Medical mycology. 57(5):573-81.

20. Mora-Duarte J, Betts R, Rotstein C, Colombo AL, ThompsonMoya L, Smietana J, et al. (2002) Comparison of caspofungin and amphotericin B for invasive candidiasis. New England Journal of Medicine. 347(25):2020-9.

21. Vigezzi C, Icely P, Dudiuk C, Rodríguez E, Miró M, Castillo G, et al. (2019) Frequency, virulence factors and antifungal susceptibility of Candida parapsilosis species complex isolated from patients with candidemia in the central region of Argentina. Journal de mycologie medicale. 29(4):285-91.

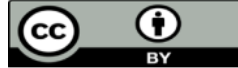

This work is licensed under Creative

Commons Attribution 4.0 License

To Submit Your Article Click Here:

Submit Manuscript

DOI: $10.31579 / 2688-7517 / 241$

Ready to submit your research? Choose Auctores and benefit from:

> fast, convenient online submission

$>$ rigorous peer review by experienced research in your field

$>$ rapid publication on acceptance

$>$ authors retain copyrights

$>$ unique DOI for all articles

> immediate, unrestricted online access

At Auctores, research is always in progress.

Learn more https://auctoresonline.org/journals/pharmaceutics-andpharmacology-research 